\title{
Traditional Atriopulmonary Connection Fontan with Excellent Outcome for 32 Years
}

\author{
Yong Zhang ${ }^{1}$ Minhua Fang ${ }^{1}$ Zengwei Wang ${ }^{1}$ Huishan Wang ${ }^{1}$ \\ ${ }^{1}$ Department of Cardiovascular Surgery, General Hospital of Northern \\ Theater Command, Shenyang, Peoples' Republic of China \\ Thorac Cardiovasc Surg Rep 2020;9:e18-e20. \\ Address for correspondence Huishan Wang, MD, PhD, Department of \\ Cardiovascular Surgery, General Hospital of Northern Theater \\ Command, 83 Wenhua Road Shenhe District, Shenyang, Liaoning \\ 110016, Shenyang 100016, Peoples' Republic of China \\ (e-mail: huishanw@126.com).
}

\author{
Abstract \\ Keywords \\ - cardiovascular \\ surgery \\ - congenital heart \\ disease \\ - coronary heart \\ disease \\ - computed \\ tomography \\ - computed \\ tomography scan
}

\section{Introduction}

The traditional atriopulmonary connection (APC) has been used in clinical practice for functional single ventricle (FSV) by Fontan et al since $1971 .{ }^{1}$ However, de Leval et al. found that pulsation of the right atrium (RA) could generate turbulence and increase the energy loss, ${ }^{2}$ total cavopulmonary connection (TCPC) has become the main procedure for FSV. Should APC be eliminated? We report a 32-year followup case with excellent outcome.

In 1987, a 5-year-old boy was admitted to our department with severe cyanosis and diagnosed as with tricuspid atresia with L-transposition of great arteries, subvalvular pulmonary stenosis, and cardiac dextroversion. Preoperative oxygen saturation of the femoral artery was $85.4 \%$. Subsequently, APC was performed. Postoperatively, the cyanosis disappeared and oxygen saturation was improved (97.4\%). During a follow-up of 32 years, he had paroxysmal supraventricular tachycardia and with a cardiac function of New York Heart Association. In addition, he had been married for 10 years and had a healthy son.

received

June 7, 2019

accepted

December 6, 2019
DOI https://doi.org/

10.1055/s-0040-1708528. ISSN 2194-7635.
After a 32-year follow-up, cardiac computed tomography angiogram (CTA), catheterization, angiography, and emission computed tomography (ECT) were performed recently.

CTA ( - Fig. 1 ) shows that the pulmonary artery (PA) trunk has been anastomosed with RA, while there is no stenosis between RA and PA.

Catheterization ( $\mathbf{- T a b l e ~} \mathbf{1}$ ) shows that the PA pressure $(12.5 \mathrm{~mm} \mathrm{Hg})$ and the whole pulmonary vascular resistance (2.21wood) are normal, the pulse pressure difference is approximately 7 to $9 \mathrm{~mm} \mathrm{Hg}$ (left $20 / 11 \mathrm{~mm} \mathrm{Hg}$ and right $18 / 11 \mathrm{mmHg}$ ), while the vena cava pressure is just a little higher (superior 19/10 $\mathrm{mm} \mathrm{Hg}$ and inferior 18/11 mm Hg).

Angiography (-Fig. 2 and - Video $\mathbf{1}$ ) shows that the blood flow from superior vena cava (SVC) and IVC (inferior vena cava) is mixed in the large RA thoroughly and then distributes to left and right PA uniformly, which accompanied by pulsation of bilateral PAs. Electroconvulsive therapy (-Fig. 3) quantitatively shows that the blood flow distributes to left (53.18\%) and right (46.82) PA uniformly (-Table 2).
License terms Stuttgart - New York 


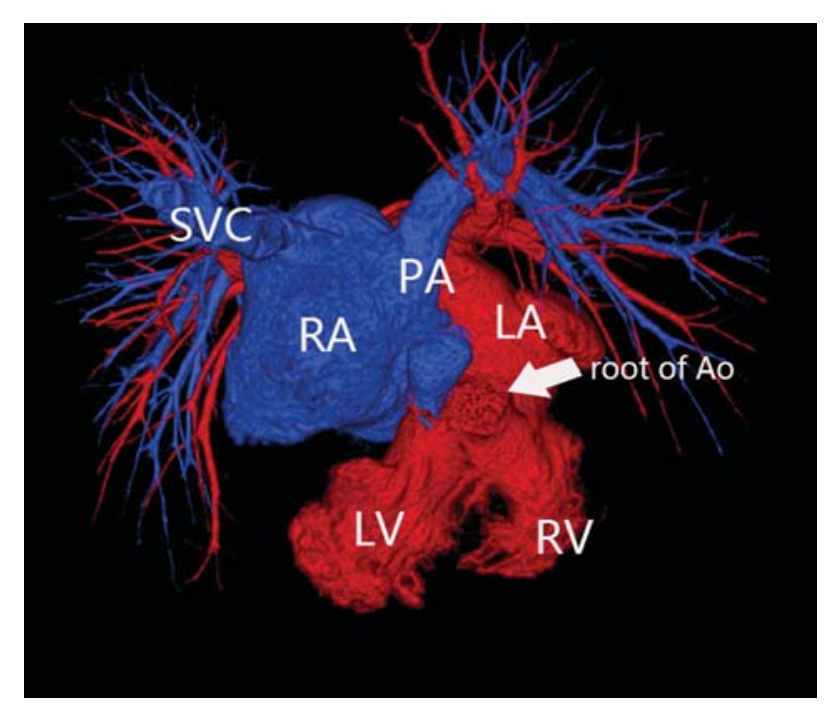

Fig. 1 Postoperative cardiac computed tomography angiogram. Cardiac dextroversion, Ao arises from the rudimentary RV; Ao is anterior and to the left of the pulmonary trunk (L-transposition); pulmonary trunk has been ligated above pulmonary valve. There is no stenosis in the anastomotic orifice between the RA and the pulmonary trunk. Ao, aorta; LA, left atrium; LV, left ventricle; PA, pulmonary artery; RA, right atrium; RV, right ventricle; SVC, superior vena cava.

Table 1 Postoperative cardiac catheter data

\begin{tabular}{|l|l|l|l|}
\hline & $\begin{array}{l}\text { Oxygen } \\
\text { saturation (\%) }\end{array}$ & $\begin{array}{l}\text { Pressure } \\
(\mathrm{mm} \mathrm{Hg})\end{array}$ & $\begin{array}{l}\text { Resistance } \\
\text { (Dyn.s.cm }^{-5} \text { ) }\end{array}$ \\
\hline SVC & 74.7 & $19 / 10(13)$ & \\
\hline IVC & 84.7 & $18 / 11(12)$ & \\
\hline L-PA & 82.9 & $20 / 11(13)$ & \\
\hline R-PA & 78.6 & $18 / 11(12)$ & \\
\hline $\begin{array}{l}\text { Residual } \\
\text { PA-trunk }\end{array}$ & & 12.5 & \\
\hline $\begin{array}{l}\text { Whole } \\
\text { pulmonary }\end{array}$ & & & 176.87 \\
\hline $\begin{array}{l}\text { Femoral } \\
\text { artery }\end{array}$ & 97.4 & & \\
\hline
\end{tabular}

Abbreviations: IVC, inferior vena cava; L-PA, left pulmonary artery; PA, pulmonary artery; R-PA, right pulmonary artery; SVC, superior vena cava.

\section{Video 1}

The blood flow from SVC and IVC is mixed in the large RA thoroughly and then distributes to left and right PA uniformly, which accompanied by pulsation of bilateral PAs. IVC, inferior vena cava; PA, pulmonary artery; RA, right atrium; SVC, superior vena cava. Online content including video sequences viewable at: https://www.thieme-connect.com/products/ ejournals/html/10.1055/s-0040-1708528.

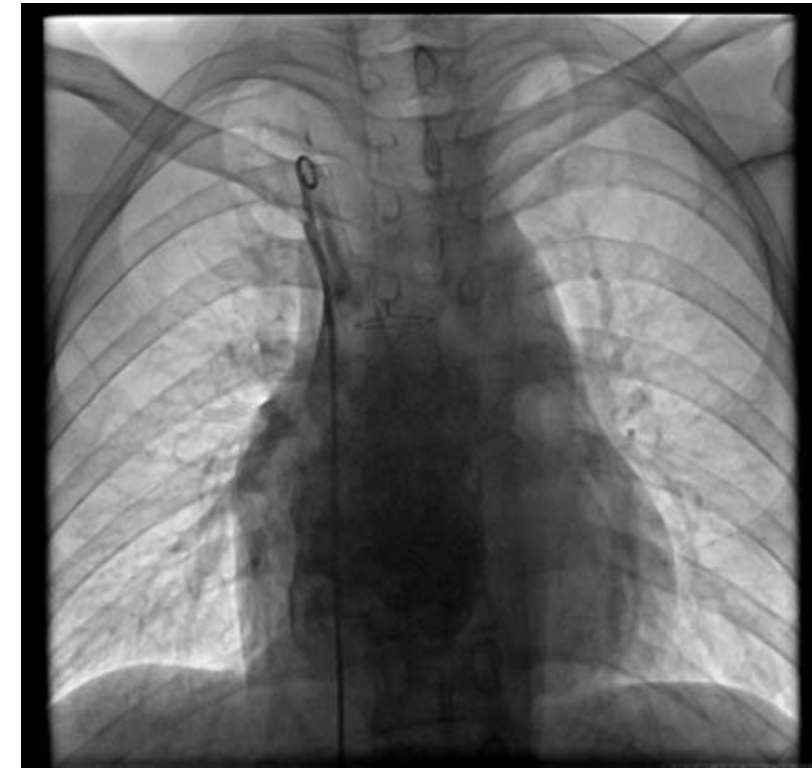

Fig. 2 Postoperative angiography.

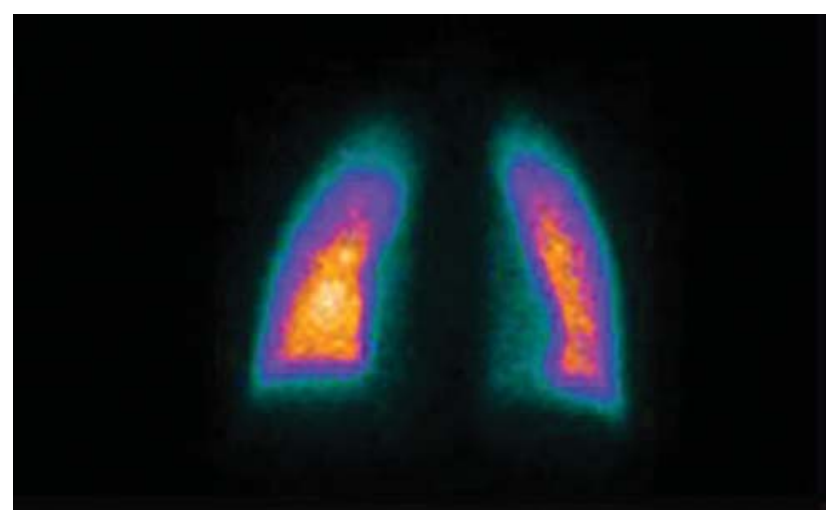

Fig. 3 Postoperative electroconvulsive therapy. Blood flow was evenly distributed in both lungs postoperative angiography.

Table 2 Postoperative emission computed tomography

\begin{tabular}{|l|l|l|}
\hline & Left lung (\%) & Right lung (\%) \\
\hline Upper & 12.95 & 8.96 \\
\hline Middle & 25.01 & 22.76 \\
\hline Lower & 15.22 & 15.11 \\
\hline Total & 53.18 & 46.82 \\
\hline
\end{tabular}

\section{Discussion}

In 1988 , de Leval et $\mathrm{al}^{2}$ reported a hydrodynamic study regarding the traditional Fontan procedure (APC) and found that pulsation of the RA could generate turbulence, which hindered the forward flow and increased the energy loss, especially around corners.

However, this patient just has performed paroxysmal supraventricular tachycardia without other complications after the APC for 32 years. In addition, oxygen saturation 
and left ventricle function are normal, while the vena cava pressure is slightly elevated. The patient was treated with oral metoprolol, regular reexamination of electrocardiogram. The radiofrequency ablation is planned to be performed for arrhythmia in the future.

For this patient, we find that the special anatomical structure (L-transposition and dextroversion) makes the left ventricle compress the hypertrophic RA to form a powerful pump, thereby promoting the systemic venous blood into the PA. Then rhythmic heartbeat brings pulsating pulmonary blood flow, which helps maintain normal pulmonary vascular resistance. On the other hand, the blood from IVC and SVC is fully mixed in RA; the blood of hepatic vein can distribute evenly to both pulmonary arteries, thus reducing the occurrence of pulmonary arteriovenous fistula.

The traditional APC has gradually been replaced by the TCPC. ${ }^{3,4}$ However, should the APC be eliminated? Although RA could generate turbulence and increase the energy loss, the pulsation of RA also provides energy for PA flow. Therefore, the traditional RA-PA Fontan may be an alternative surgical procedure for some special patients because of the good outcome.

Funding

None.

\section{Conflict of Interest}

No conflict of interest exits in the submission of this manuscript.

\section{References}

2 Fontan F, Baudet E. Surgical repair of tricuspid atresia. Thorax 1971;26(03):240-248

2 de Leval MR, Kilner P, Gewillig M, Bull C. Total cavopulmonary connection: a logical alternative to atriopulmonary connection for complex Fontan operations. Experimental studies and early clinical experience. J Thorac Cardiovasc Surg 1988;96(05):682-695

3 Dabal RJ, Kirklin JK, Kukreja M, et al. The modern Fontan operation shows no increase in mortality out to 20 years: a new paradigm. J Thorac Cardiovasc Surg 2014;148(06):2517-23.e1

4 Ly M, Roubertie F, Kasdi R, et al. The modified Fontan procedure with use of extracardiac conduit in adults: analysis of 32 consecutive patients. Ann Thorac Surg 2014;98(06):2181-2186 